\title{
NEO-NO-BARROCO O BARROCOCÓ: HACIA UNA PERSPECTIVA MENOS INEXACTA DEL NEOBARROCO
}

\author{
Eduardo Espina \\ Texas A\&M University \\ edespina@yahoo.com
}

\section{RESUMEN/ABSTRACT}

Este ensayo analiza las nociones estéticas principales que definen la llamada poética neobarroca. $\mathrm{Al}$ respecto, presenta elementos para justificar la utilización de los vocablos neo-no-barroco y barrococó en vez de "neobarroco", por considerar a este término erróneo, pues proyecta la idea -por el uso del prefijo- que es descendiente directo del barroco español, algo que es una verdad incompleta. La relación del neo-no-barroco/barrococó con la idea fundacional del Romanticismo, de que la poesía debe pensar sobre el pensamiento, es obvia y sin embargo no ha sido debidamente analizada. Por lo tanto, al haber una reconfiguración etimológica de la estética asociada con la dificultad y la superposición de escollos retóricos que le exigen al acto de la lectura una mayor concentración, la poética neo-no-barroca o barrococó podrá alcanzar una más exacta definición y permitirá incluir voces poéticas hasta ahora no consideradas neobarrocas.

PALABRAS ClAVE: neo-no-barroco, barrococó, reconfiguración, dificultad, superposición.

This essay reflects upon the principal aesthetic notions that define the so-called Neobaroque poetic. In this regard, new evidence is presented in order to justify the use of two words (synonymous), neo-no-barroco and barrococó instead of "Neo-baroque", considering this term a misnomer since it projects the idea-by the use of the prefix-that it is a direct descendent of the Spanish Baroque, which is an incomplete truth. The relationship of the neono-barroco / barrococó with the foundational idea of Romanticism; that poetry should think about thinking is obvious and yet, it has not been adequately analyzed. Therefore, having an etymological reconfiguration of the aesthetic associated with difficulty and with the overlapping rhetorical pitfalls that demand the act of reading at a higher concentration level, the neono-barroco or barrococó poetic will be able to reach a more precise definition and allow the inclusion of poetic voices hitherto unconsidered as Neobaroque.

KEYWORDS: neo-no-barroco, barrococó, reconfiguration, difficulty, overlapping. 
A Emeterio Cerro (1952-1996), neo-no-barroco hasta la ruina final.

Por carecer de un término preciso para definir y tratar de entender el complejo y desconcertante tiempo histórico y estético situado entre ambos siglos, el XX y XXI, y lo que vino después -donde estamos-, la crítica ha recurrido al término neobarroco a la hora de determinar todo aquello que supuestamente genera dificultad de comprensión o presenta una versión fragmentada y expansiva de la realidad, sea empírica o literaria. El término, de extraordinaria ubicuidad, tiene hoy en día tanto uso como en un momento -décadas de 1980 y 1990- lo tuvo la palabra "posmodernidad". Sufre el mismo manoseo. Si algo no se entiende, es llamado "neobarroco". Ante cualquier espesor o lugar a dudas de difícil acceso mediante el raciocinio, se recurre con gran liviandad a la polifuncional locución. Por ejemplo, al menú de un restaurante que por ser fusión de distintas gastronomías hace inclasificable al tipo de cocina, se le llama "neobarroco"; un tipo de indumentaria prêt-à-porter que mezcla indiscriminadamente tendencias es considerada "neobarroca"; a un rascacielos donde estilos pasados y presentes coinciden sin una funcionalidad precisa se le denomina "neobarroco" (se utilizó el término para referir a la arquitectura de Frank Gehry), etc.

Hasta los medios informativos y las redes sociales se han apropiado antojadizamente del vocablo, lo han avasallado. Y como si el uso viral del mismo fuera poco, la exageración reiterada ha llevado a articular una clasificación imprecisa y espuria, esto es, a suponer que el neobarroco literario desciende directamente del barroco español, y que el neobarroco latinoamericano habría tenido un comienzo en cierto momento del siglo XX y también un único iniciador (José Lezama Lima). Nada más inexacto y apresurado que ambas reducciones. Se ha ido por el camino más fácil. Por la tangente. El presente ensayo busca aportar, por lo tanto, una perspectiva más próxima a los reales ingredientes discursivos, al repertorio unificador de la única escritura original de nuestra época, una que tiene infinidad de procedencias, perspectivas y resoluciones formales, y presenta asimismo características vinculantes y comunes a determinadas prácticas de escritura poética ocurriendo en nuestro tiempo de manera simultánea.

Tal pareciera -y el presente de indicativo podría con facilidad sustituir al subjuntivo- que el neobarroco está de moda. El siglo XXI comenzó bajo el aura de ese ímpetu. Hasta la crítica marxista le presta atención al 
fenómeno. Por consiguiente, si para que fuera tema de estudio mejor tratado el neobarroco debería pasar de moda, entonces, bienvenido eso. Aunque, dadas las circunstancias, y considerando que por ser residentes de una muy vigente "era neobarroca" eso difícilmente vaya a suceder, convendría afinar el oído para interpretar la melodía de la época de acuerdo a su tono y no a la interpretación incompleta que se le pueda ocurrir al escucha. En carta fechada el 28 de noviembre de 1914, y escrita en respuesta a un amigo que le había enviado los poemas "Helian", "Kaspar Hauser Lied", y "Abendland" de George Trakl, Wittgenstein, a quien la poesía de Rilke le parecía artificial, afirmó: "Le agradezco por el envío de los poemas de Trakl. No los entiendo, pero su tono me pone feliz. Es el tono del hombre verdaderamente genial" (Von Ficker $53)^{1}$. Pues, muy simple, se trata de eso; de acceder con argumentos válidos al "tono" detectado de una genialidad que no necesita ser comprendida, pero que es propia, intransferible, de una forma de escritura que tiene confianza absoluta en el lenguaje y en su alcance más allá de la comunicación inmediata. No en vano, una y otra vez oímos al yo del lenguaje adquirir su personalidad, recuperar una capacidad elocutiva anterior o no existente, la cual confirma la "desaparición elocutiva del poeta" a la que hacía referencia Mallarmé.

Verdadero mecanismo de reanimación que le ha permitido al idioma dar un paso adelante, el neobarroco, al que de aquí en más convendría llamar neo-no-barroco o barrococó para otorgarle más precisión a un ente estético impreciso y absorbente, es el sitio efusivo donde ir a escuchar lo indecible ${ }^{2}$. La poesía como neolengua y retrato oblicuo de la escritura; con sus

1 En carta posterior, fechada el 13 febrero 1915, Wittgenstein tuvo una opinión diferente sobre el tono de la poesía de Rabindranath Tagore: "La impresión que me da es que toda esa sabiduría sale lista del congelador; no me sorprendería del todo que él ha sacado de libros o escuchado por ahí (en realidad, tal como nosotros hemos adquirido la sabiduría cristiana), sin haberla sentido el mismo. Es posible, sin embargo, que no haya entendido yo su tono; pero este no me parece ser el tono de un hombre agarrado por la verdad. (Como el tono de Ibsen, por ejemplo"; Von Ficker 46).

En entrevista realizada por la poeta argentina Romina Freschi, y publicada en la revista plebella (\#18, Buenos Aires, diciembre 2009/marzo 2010"), ante la pregunta, "en su momento te sumaste al neobarroco a través del término barrococó ¿podrías explicarnos la diferencia y el acercamiento de tu poesía al neobarroco a través del barrococó?", respondí lo siguiente, lo cual ayuda a entender el origen del neologismo: "En verdad no me "sumé", me sumaron. Cuando en 1982 publiqué Valores personales, mi primer libro, en el Río de la Plata éramos pocos entre los recién llegados los que ejercíamos una sintaxis de riesgo y diversificación del tono y la prosodia. Según un libro de crítica en etapa de publicación, Neobarrosos. Los fundadores, éramos apenas cinco (en Uruguay solo Echavarren y yo). Sin 
consecuencias preferibles, con su afán por llevar la expresividad hasta las últimas consecuencias, impone una profundidad exterior, una excepcionalidad al alcance de lo inadecuado, según la cual el raciocinio pasa a tener representatividad limitada. Triunfan las bifurcaciones con trayectoria a cualquier recoveco del pensamiento; el enmascaramiento, la sobredeterminación. También, la reconstrucción en dirección opuesta de las palabras, tal cual consiguen ser una vez libradas de su condición de intermediarias de un posible mensaje y de una comunicación específica, pasando ahora a moverse mediante sustituciones sintácticas sin causalidad. En medio de una distorsión poética acústica saturada de riffs, afín a la del rock heavy metal (pero con mucho de

embargo, puesto que en nuestro continente la crítica sobre poesía es casi inexistente y la poca que hay en su mayoría desconoce bastante la historiografía literaria, se habla y se toca de oído al intentar analizar un fenómeno irrepetible como el neobarroco, es decir, se ejerce la ignorancia burdamente, desconociendo libros, datos y riesgos asumidos fuera del libreto de la tradición. Yo venía haciendo lo mío desde mucho tiempo antes de publicar Valores personales, algunos de cuyos poemas salieron incluso en revistas tiempo antes. Cuando el libro se editó, en Uruguay no salió ni una sola reseña, acto que en su momento me sorprendió y que hoy me reconforta viendo a la distancia las cosas que elogiaba la crítica uruguaya en ese momento. En 1983, estando yo viviendo en Wichita, Kansas, ciudad que aparece mencionada en poemas de Pound, Ginsberg y Cardenal, entre otros, recibo una carta proveniente de Sao Paulo de un poeta que yo entonces desconocía y que tampoco había leído, Néstor Perlongher. Una carta amable, lúcida, en la cual decía en uno de sus pasajes, refiriéndose a Valores personales (libro que, como supe después, le había enviado Reinaldo Arenas): "Vos sos neobarroso, ¿dónde habías estado?". Me sorprendí, pues nunca había escuchado esa palabra antes, pero sobre todo por el hecho de que alguien me considerara así cuando yo creía que lo mío, tal como le dije luego a Perlongher conversando en París, en aquel mayo de 1990, era barrococó, pues yo había llegado al Barroco en viaje hacia atrás, pasando primero por el Rococó, esa periferia artística en la cual lo mundano, librado de todo artificio mistificante, impone una minuciosidad detallista, una mitología de las cosas establecida una vez superada la condición de mediadoras decorativas que estas tenían. El Rococó siempre me ha conmovido por su impostura configurativa anacrónica, tan rechazada por el dogmatismo visceral de la crítica neopositivista (hoy ideológica), para la cual el Rococó (nombre que alude a una composición de "rocaille", piedra, y "coquille", concha marina) representa lo espurio de la historia, el iterativo desecho visual de la realidad. El Rococó es la fiesta pagana de las formas y en el medio de la gran parranda de alternativas formales entabla relación con el Barroco, en tanto ambos coinciden -bingo- en una espesura blindada milimétricamente, construida en base a relieve, declive y pliegue. La Venus barroca y renacentista de Sandro Botticelli se encuentra parada en la "coquille" o concha marina donde luego se vino a parar la estética rococó, la cual anticipó las pautas para pasar de lo figurativo a lo abstracto, mejor dicho, a ese intersticio al borde de lo sublime, donde lo figurativo y lo abstracto dialogan superpuestos, al que llamo barrococó (porque la concha es de barro y de arrorró su sonido)". 
jam session), de una dicción polifónica a la cual le salen acontecimientos, lo sublime emerge como preservación de efectos y suma de intervenciones en la incertidumbre. A esa experiencia radical del habla los estadounidenses la llamarían "experimental", performativa. Recurrirían al vocablo acumen: el punto de vista tiene la capacidad para existir por su propia cuenta.

En el que fue denominado "Primer Encuentro de la Poesía Neobarroca", organizado por el poeta colombiano Armando Romero, realizado con gran asistencia de público en la Universidad de Cincinnati en 1988, varios años antes de que se publicara Medusario: muestra de poesía latinoamericana (1996), y en el que participaron como poetas invitados José Kozer, Roberto Piccioto y quien esto escribe, Samuel Gordon, catedrático de poesía contemporánea de la Universidad Nacional Autónoma de México (UNAM), y uno de los primeros en destacar que la novedad neobarroca se extendía por distintas partes del continente hispano-hablante con incontenible furor, afirmó, en lo que es hoy una frase de marca registrada: "Atacan tanto al neobarroco pues temen que entre al canon; pero los ataques llegan tarde; el neobarroco ya entró al canon". La profética afirmación de Gordon vino a quedar demostrada en la realidad de los hechos permanentes cuando en 2012 se publicó la cuarta edición del Princeton Encyclopedia of Poetry and Poetics, y en la cual el término "neobarroco" tiene su propia entrada (páginas 927 y 928).

Desde la aparición del boom de la novela latinoamericana, en la década de 1960, ninguna otra expresión referida a la literatura latinoamericana había recibido un destaque similar en dicha enciclopedia. El neobarroco quedaba confirmado como el modernismo de nuestra época, una convergencia de poéticas en diálogo mutuo. Tal cual la más prestigiosa publicación en el mundo de términos literarios lo atestigua, el neobarroco ha entrado en el vocabulario crítico de la academia y es parte irrefutable del canon $^{3}$. Las revoluciones difícilmente pueden ser institucionalizadas (el Partido de la Revolución Institucional, el PRI mexicano, quizá sea la excepción o el colmo, depende de cómo se lo vea), pero las revoluciones lingüísticas de orden literario pueden

\footnotetext{
Entre los ciclos y simposios organizados en la academia estadounidense cabe destacar, por su carácter reciente y duración, Variable Topics: la máquina barroca, que consistió de conversaciones y lecturas poéticas con los poetas José Kozer, Roberto Echavarren, Eduardo Espina, Raúl Zurita y Coral Bracho (en ese orden, uno cada tres semanas). Fue organizado por las poetas Lila Zemborain y Mariella Dreyfus, del departamento de Español y Portugués de New York University, docentes del seminario graduado de escritura creativa durante el semestre de primavera (febrero-abril) de 2014.
} 
tener presencia destacada en las ordenaciones taxonómicas de raigambre académica, designadas para entender un determinado periodo de la historia y una manera de escribir con su propio peso. Gertrude Stein dijo en 1926 que el creador de la "nueva composición en las artes es un proscripto hasta que es un clásico, sin que difícilmente haya un momento en medio". Pues, bien, sin que hubiera habido "un momento en medio", el neobarroco ha dejado de ser y de estar "proscripto".

Sin embargo, más allá de su tan frecuente uso, el término neobarroco ha sido víctima reiterada de la arbitrariedad etimológica y del destrato retórico cercano a la ignorancia en acción (producto de esta). Posiblemente la ignorancia y las lecturas de superficie hayan sido cómplices para conformar un espectro de interpretaciones erróneas, inexactas, y para peor, peligrosamente generalizadoras. Hablar de neobarroco hoy en día implica activar una vaguedad, darle cabida a un término en fuga. La definición -algo también muy cuestionable- solo podría aceptarse para detectar y advertir "lo que no es"; para distanciarse de obras y poetas que no son neobarrocos, que nunca lo fueron, y que sin embargo más de uno se animó a etiquetar de esa forma, por haber notado ciertos gestos afines a la fachada de su escritura. De noche todos los gatos son pardos. Algo así. Pero cuidado.

Pablo Neruda no es neobarroco (le hubiera gustado, pero su adicción a las metáforas lo afectó); Vicente Huidobro no lo es; tampoco Jorge Luis Borges (es barroco en sus ensayos, un Baltasar Gracián moderno, también en el cuento "Pierre Menard, autor del Quijote", aunque hablara con desprecio de toda literatura donde hubiera "barroquismo"); no es neobarroco César Vallejo (solo y en parte lo es en Trilce, en el resto su lacrimoso sentimentalismo es de bolero); Oliverio Girondo ejerce una escritura neobarroca en cuotas y de manera acotada (aunque por el furor entusiasta que recorre su obra debería ser considerado miembro privilegiado del elitista club), y Julio Herrera y Reissig y José Lezama Lima, claro está, pueden ser considerados referentes neobarrocos en épocas diferentes, cada uno con distinto arsenal sintáctico y retórico, por más que el poeta cubano suele ser presentado como supuesto iniciador de lo neobarroco "latinoamericano", tal vez por el gran trabajo de 'branding' que hizo Severo Sarduy.

Herrera y Reissig y Lezama Lima provienen del barroco español (sería una majadería intentar argumentar lo contrario), pero ambos pasaron como esponjas en actividad por la poesía francesa del siglo XIX, que con Baudelaire, Rimbaud, Lautréamont y Mallarmé inventaron un habla furiosa nada renuente, a la que se le fueron agregando luego nuevos componentes, siendo 
precisamente eso lo que ha hecho la poesía posterior añadir ingredientes, tal como lo hizo la de la primera modernidad, incluida la anglosajona (algo que la crítica inglesa y estadounidense suele olvidar con frecuencia), pues T. S. Eliot, el primer poeta moderno en lengua inglesa ("The Love Song of J. Alfred Prufrock" se publicó en 1915), es descendiente directo, primera generación, de Jules Laforgue, y así sucesivamente, para atrás y para adelante.

Herrera y Reissig conoció y tradujo antes que nadie a Saint Pol-Roux (uno que se le pasó a Rubén Darío, quien conoció a Lautréamont, pero lo leyó mal o no quiso leerlo bien), considerado el "padre del surrealismo" por André Breton y el grupo surrealista. Herrera y Reissig (1975-1910), un desquiciado intencional, vio en el inconsciente, que por esa misma época desvelaba a Freud, a un amigo ideal para revitalizar el habla de la mente, pero justo cuando estaba por seguir descubriendo territorios verbales inéditos se murió muy antes de tiempo, dejando a medio terminar una obra prevanguardista y neobarroca. Sin haberlos nunca usado, fue el precursor de los prefijos modernos ${ }^{4}$.

Doce años después de la muerte de Herrera y Reissig, César Vallejo radicalizó en Trilce la tarea de desmantelamiento y reversión iconográfica, retórica y sintáctica dejada inconclusa por Herrera y Reissig (por más que "La Torre de las Esfinges", primer monumento neobarroco de la poesía latinoamericana, pueda verse como un logro fenomenal y acabado), algo que el propio poeta peruano reconoció en carta a su compatriota, el poeta Xavier Abril. Vallejo amortizó con continuidad de ruptura la deuda contraída con las invenciones, sobre todo en el plano sintáctico y prosódico, del poeta uruguayo, quien llevó al torrente verbal del inconsciente -y su relación con la vida onírica- en un vertiginoso viaje de solo ida por la empinada montaña rusa. Lezama Lima, en cambio, nunca entendió bien al surrealismo, incluso lo vio con reiterado desdén, habiéndose aproximado en esa misma época, cosa aún inaudita y difícil de aceptar (incomprensible), más a la poesía de Juan Ramón Jiménez que a la de Antonin Artaud, por ejemplo. Que alguien, si puede, lo explique.

En fin. Por lo tanto, ¿de qué hablamos cuando hablamos de "neobarroco? ¿A qué le llamamos "neobarroco"? El término engaña por una cuestión

$4 \quad$ El crítico y escritor chileno Yolando Pino Saavedra (1901-1992) fue el primero en haberse ocupado, y con rigor, de la obra del poeta uruguayo, al publicar el libro La Poesía de Julio Herrera y Reissig (Santiago: Universidad de Chile, 1932), notable lectura no solo de la obra estudiada, sino también de las formas que iba adquiriendo la poesía moderna. 
de fondo: hace creer, por ejemplo, que la poesía neobarroca, surgida en el Río de la Plata a principios de la década de 1980 (con casos muy contados con la mano) y cuyos puntos de afinidad en el continente americano eran las poéticas de José Kozer (cubano viviendo en Nueva York) y Gerardo Deniz (español viviendo en la Ciudad de México), es decir, escribiendo "lo mismo" en otras partes, esa poesía pues, que rápidamente fue metida en la bolsa de lo inclasificable y considerada parte de un "movimiento" literario aunque no lo fuera (nunca se escribió un manifiesto, tal como hicieron los surrealistas), provenía directamente del barroco español. Si bien hay vasos comunicantes con parte del barroco español y con barrocos en otras lenguas (el trato riguroso de la sintaxis, la eufonía, los ritos prosódicos), el resultado final incluía orígenes diversos, como también propósitos indeterminables y de dispersa multiplicidad, la mayoría sin relación alguna con el barroco español.

Considerados los antecedentes, y por respeto a una definición menos anfibia del fenómeno literario y sus especificidades, cabría tal vez, mejor dicho, convendría, hablar de neo-no-barroco o barrococó, en vez de neobarroco para definir el espectro en constante aparición y disolución de una poética multiforme y coral que atraviesa el lenguaje como excavadora y máquina demoledora, convencida de que solo al "otro lado" de las palabras la mente tiene algo para decir y va a decirlo como quiere, sin sentirse responsable de la "comunicabilidad" o no de las palabras elegidas para interpelarla. El emprendimiento de interpretación saca de quicio a cualquier intento por hallar significado donde no es cuestión de que lo haya o no, sino que siempre hay más de uno. En ese plus de desbordes, pero también de autocontención (en la fina línea en medio corre la veta neo-no-barroca: al exacerbar su cometido, el lenguaje se intelectualiza). Todo pasa por la mente, por lo que la poesía pasa a ocuparse del todo justo cuando está pasando 5 .

En esta acometida de la simultaneidad, esto es, en el desafío por acomodar el habla a todo lo que le ocurre cuando entra en actividad, resulta imposible

$5 \quad$ Al respecto, conviene revisar el poema de José Kozer, "Véase, como dice Eduardo Espina, que es todo mental", incluido en el libro Índoles (2013), que incluye una "propedéutica lírica" de la poesía neobarroca (cito un pasaje fundamental del mismo): "Diez,/ quince minutos en/ que no tengo sombra,/ no hay pensamiento,/ siento el acto de la/ limpieza como si me/ adentrara en una/ morada más interior,/ una de aquéllas que/ elaborara Santa/ Teresa en su visión,/ vaya coco el mío". Al respecto y para ir definiendo de una vez por toda la poética neo-no-barroca, resulta imprescindible el ensayo de Kozer, "El neobarroco, una convergencia en la poesía latinoamericana": http://www.revistasolnegro.com/sol\%20negro/josekozer.html 
resumir la totalidad del pensamiento en un solo punto de vista. ¿No fue eso mismo lo que hicieron, por nombrar solo a algunos, Hieronymus Bosch, Pieter Brueghel, Giuseppe Arcimboldo, Arnaut Daniel, Maurice Scève, Lautréamont, Robert Browning (en Sordello), Lewis Carroll, Alban Berg, Arnold Schoenberg - de cuyas composiciones Janik y Toumlin afirmaron que "representan ataques en contra de la pseudosofisticación del esteticismo burgués" (66)-, o el cine de David Lynch, sobre todo su filme Inland Empire? ¿Son considerados neobarrocos? No. Entonces, ¿deberían ser considerados? Por qué no. ¿Por qué no ir para el otro lado y agregarle al neobarroco otras acepciones terminológicas, otras prácticas estéticas lindantes o análogas? ¿Por qué no darle un nombre más receptivo a desvíos y variaciones que lo sitúe en su real dimensión en el siglo XXI, por donde transita esparciendo su aura como sinónimo de "hálito de la época"?

Aunque neo-no-barroco o barrococó resulten términos más propicios para contener en su multiplicidad de opciones formales la poética a consideración, al mismo tiempo el presente destaca que cambiarle en estos momentos el nombre al producto, y dejar de llamarlo neobarroco, sería una mala idea. Después de haber llegado al Princeton Encyclopedia of Poetry and Poetics sería contraproducente. Además, la palabra "neobarroco" es una señal identitaria de un determinado momento de la historia, con tan amplio uso como rock and roll. Sin embargo, al mismo tiempo mantener la etiquetación, tan imprecisa en contenido y procedencia, podría acelerar el proceso de desgaste anfibológico y acuñar un vocablo similar a, por ejemplo, "supermercado", en el cual formas y argumentos diversos conviven en una forma excesivamente democrática, favoreciendo a fin de cuentas la indefinición y el todo vale denominativo. El neobarroco es hoy un ente, un camaleón etimológico, al que no es fácil entrar ni salir con una definición precisa, por más que la mayoría sepa de qué hablamos cuando hablamos de neobarroco. Es una especie de alien que genera réplicas, siendo la mayoría de ellas falsas impostaciones, copias no certificadas de lo que no es, pero podría llegar a ser. A diferencia de la tan repetida premisa de Marshall McLuhan, "el medio es el mensaje", aquí "el lenguaje es el mensaje". La fe en este, en el lenguaje, hizo del neobarroco una teología carente de sustitutos.

El neobarroco es la aceptación de todo lo que no puede ser de otra manera, y como esa certeza salta rápidamente a la vista (la estrategia de ocultación de evidencias es una de las bases de esta poética) conduce a una intolerable generalización de la forma de ver las formas, de ocupar el sentido del sinsentido. No obstante, pese a la invitación que la escritura mantiene permanentemente 
abierta, en términos generales (salvadas las honorables excepciones), crítica y academia no han sabido hasta ahora poner en perspectiva los alcances de esta poética contemporánea en expansión, que venía de antes y que ha seguido después (en el ahora donde estamos). Ante el defecto metodológico consecuencia de la falta de una clasificación precisa, tal parece que se hubiera comenzado a usar el primer nombre disponible, "neobarroco", al cual en el idioma español, en el castellano de América al que refería Andrés Bello, se le han asociado las poéticas de la dificultad. En muchos aspectos aún estamos en un constante punto de partida, en un empuje originario que no cesa ni nos deja. Convendrá entonces referir a los materiales que componen los pilares del tipo de escritura a consideración.

El neobarroco poético latinoamericano, orquesta de muy pocos miembros, tuvo su eclosión a principios de la década de 1980, sin haber todavía perdido vigencia. Fechas y periodo histórico no son arbitrarias ni pueden ser soslayadas. La época comenzaba a evidenciar un agotamiento de las formas literarias que por entonces eran moneda corriente, asfixiadas en el Cono Sur por los gobiernos de facto, pero también por la falta de alternativas formales a corto plazo. Ya entonces se vivía (¿"pre-vivía”, ya que transitamos la era del prefijo?), la angustia del fin de siglo y de milenio, la cual llevó a creer que con el siglo se acababa una época de la historia, y que una suma de posibles catástrofes separadas venían a tomar control de la realidad. No en vano hubo un verdadero boom (aún no estudiado) de libros alarmistas referidos al estado de la realidad al fin de milenio, la mayoría de ellos de origen anglosajón; The Closing of the American Mind (1987), de Allan Bloom, El fin de la Historia y el último hombre (1992), de Francis Fukuyama, El choque de civilizaciones y la reconfiguración del orden mundial (1996), de Samuel P. Huntington, y Fashionable Nonsense: Postmodern Intellectuals'Abuse of Science (1998), de Alan Sokal y Jean Bricmont, sin olvidar al pensamiento académico francés, popular en esos días de ansiedad global, con libros de amplia circulación como La condición posmoderna (1979), de Jean-François Lyotard, El imperio de lo efímero (1987), de Gilles Lipovetsky, y La Ilusión del Fin (1993), del por entonces omnipresente Jean Baudrillard, entre otros varios.

Con la época se acababa la originalidad. La imaginación claudicaba. En ese contexto de fatalismo mundial, el neobarroco vino a traer una estética de originalidad en varios frentes, saliendo airoso incluso de las mecánicas lecturas de los críticos que lo situaban en un espacio de continuidad manifiesta, procedente a grandes rasgos del barroco europeo (el neo apunta a una descendencia directa), sobre el cual Gilles Deleuze reflexionó en su libro Le 
pli: Leibniz et le Baroque, ambicioso pero incompleto intento de comprensión, pues el bien argumentado análisis se queda corto a la hora de entrar al fondo de la estética neobarroca y de los registros formales que marcan su diferencia, quedándose en abstracciones demasiado generales, desprovistas de argumentos minuciosos aplicables con mayor especificidad a la poética a consideración, sin conseguir por ello dar en el blanco y demostrando una reticente capacidad de entendimiento (aunque sí de empatía) del des-pliegue retórico y del re-pliegue sintáctico, los cuales, a fin de cuentas, son el principal sostenimiento de la poética neobarroca, en tanto ahí se establecen los principios fundacionales del procedimiento de escritura, del pensar sobre un pensamiento que sale a buscar lenguaje equipado únicamente de lenguaje.

El barrococó o neo-no-barroco (por no venir sola y directamente del barroco ni ser tampoco un mero apéndice de este) latinoamericano de la década de 1980 fue una "coincidencia" o "convergencia" de originalidades. De ahí que no sea arbitraria la relación que tienen con el modernismo, en el cual pasó algo similar. Decir que el neobarroco fue o es un exclusivo Club de Toby no implica modificar la verdad, pues las tres mujeres que aparecen en Medusario (muestra que incluye un total de 22 poetas), Marosa di Giorgio, Tamara Kamenszain y Coral Bracho, poetas con obra valiosa las tres, parecen haber sido incluidas en cumplimiento de un requisito de representatividad de género, tal vez para cumplir con algo parecido a aquello que respondió Mick Jagger cuando le preguntaron por qué habían invitado a Tina Turner a participar en el documental Gimme Shelter (en donde solo cantó una canción: "I've Been Loving You Too Long"), y si era únicamente por una cuestión de afinidades musicales: "Siempre tiene que haber por lo menos una mujer"6. Además de la exigua cantidad de poetas antologados en Medusario (el libro incluye una larga lista de poetas que fueron nominados - tal como pasa en el Oscar-, pero al final quedaron excluidos), por el camino se rezagaron unos cuantos cuyos lenguajes perdieron espesor prosódico y sintáctico, o bien su poesía se hizo 'mellow' (melosa), comunicativa de una inmediatez que no viene al caso; qué alarmante ironía: los cantantes de heavy metal terminaron cantando baladas sentimentales. La resistencia incluyó a pocos, y son esos

6 La poesía posterior de Marosa di Giorgio, Tamara Kamenszain y Coral Bracho nada o muy poco tuvo de neobarroca. En el caso de las dos últimas, se aproxima más a lo que en España llaman "poesía de la experiencia". No se trata de un juicio valorativo, sino de una realidad textual que impone un tono de oralidad cotidiana y accesible al primer intento de comprensión, con sus argumentos explícitos para la mentalidad corriente. 
pocos los que llegan activos hasta el día de hoy, validando descendencias y maneras de adentrarse en las posibilidades de la escritura ${ }^{7}$.

A fines del siglo XX y principios del XXI, con la eclosión de la cibernética y de los nuevos usos industriales, el paisaje de las ciudades se llenó de acontecimientos. El ser humano se acostumbró rápido a "ver más", sin poder determinar cuánto más era lo que veía. Lo que "estaba" dando la impresión de ser todo ya no le alcanzaba para definir su contenido y determinar qué era lo especifico de lo específico. En verdad, no era un asunto nuevo. Hemos arrastrado esa tendencia desde que la modernidad se pobló de desvíos y

7 Una lista somera de poetas en actividad con afiliación directa con la estética neono-barroca debe incluir a los siguientes: Gerardo Deniz (1934), José Kozer (1940), Roberto Echavarren (1944), Carmen Berenguer (1946), Gabriel Jaime Caro (1950), Héctor Piccoli (1951), José Morales Saravia (1954), Roger Santiváñez (1956), Reynaldo Jiménez (1959), Mario Arteca (1960), Rito Ramón Aroche (1961), Félix Batista (1964), Nakh Ab Ra (Ná Kar Elliff-ce, 1969), Javier Bello (1972), Ernesto Carrión (1977), Romina Freschi (1974), Rosario Rivas Tarazona (1975), Simón Villalobos (1980) y Pablo de Cuba (1980). También, por afinidades específicas que en algún momento presentan sus obras con la estética a consideración, debe mencionarse a los poetas: David Rosenmann-Taub (1927), Carlos Germán Belli (1927), Luis O. Tedesco (1941), Rodolfo Hinostroza (1941), Mirko Lauer (1947), Arturo Carrera (1948), David Huerta (1949), Raúl Zurita (1950), Coral Bracho (1951), Reina María Rodríguez (1952), Eduardo Milán (1952), Víctor Sosa (1956), Mauricio Medo (1965), Héctor Hernández Montesinos (1979), Elbio Chitaro (1961), Silvia Guerra (1961), Andrés Ajens (1961), José Antonio Mazzotti (1961), Luis Carlos Mussó (1970), Gabriela Bejerman (1973), Rodrigo Flores (1977), Juan José Rodríguez (1979), Juan Salzano (1980) y Juan Manuel Silva Barandica (1982). La antología Indios del Espíritu. Muestra de poesía del Cono Sur (Montevideo: La Flauta Mágica, 2013), realizada por Roberto Echavarren, reúne de manera rigurosa y bien argumentada voces pertenecientes o relacionables a la estética 'neobarroca'. Otras antologías a tener en cuenta son: Jardim Camaleões: a Poesia Neobarroca na América Latina. Organização, seleção e notas: Claudio Daniel. Tradução: Claudio Daniel, Luiz Roberto Guedes e Glauco Mattoso. Prefacio "Barroco, neobarroco, transbarroco", de Haroldo de Campos (São Paulo: Iluminuras, 2004, 256 páginas), y sobre todo la imprescindible Antología Crítica de la Poesía del Lenguaje (México, DF: Editorial Aldus. 2009, 378 pp.), de Enrique Mallén, uno de los mayores y más constantes estudiosos de la poesía neobarroca, en la que fueron incluidos solo diez poetas.

$\mathrm{Al}$ respecto puede consultarse: https://picasso.shsu.edu/mallen/ANTOLOGIA-REVIEW-1. $\mathrm{html}$ y ww.periodicodepoesia.unam.mx/index.php?option $=$ com_content\&task $=$ view\&id $=14$ 54\&Itemid $=1$

También cabe mencionar el volumen "Neobarroco y otras especies", $\mathrm{N}^{\circ} 76$ (2013), de la Revista de Crítica Literaria Latinoamericana, edición a cargo de Roger Santiváñez y Eduardo Espina. Como asimismo muy recomendables son los innovadores trabajos de investigación realizados por Mirian Pino, profesora en la Universidad de Córdoba, Argentina. 
atajos cómplices con una discontinuidad acelerada. El ciclo conduce a un caudal insatisfecho que no para de agregar realidades, imágenes, vacíos de la plenitud, estados delicados de la complejidad. Del otro lado del lugar observado terminamos aceptando que hay tanto nuevo, que son tantos los elementos que rigen la cotidianeidad, que la originalidad tiene problemas para sentirse determinada. Le ponemos nombres, ponemos atención a sus metamorfosis, y la sobrecargamos de prefijos. Hay para todos los gustos: pre-modernidad, post-modernidad, neo-historicismo, neo-barroco, poscolonial, post-industrial, neo-con, post-industrial, posvanguardista, pospornografía (expresión utilizada por primera vez por Annie Sprinkle en 1990), biocapitalismo, post-neoliberal, neomanierismo, post-contemporáneo y este, insólito, divertido: post-crítica (que suena a crítica proscrita), etc. Muchos "post" para decir que hoy todos es posterior. En fin, aún no hemos llegado a la era de los post-prefijos, pues estos siguen proliferando, desafiando la hegemonía terminológica. La sobredosis de prefijos evidencia, entre otras cosas, el agotamiento del vocabulario disponible para entender los cambiantes alrededores (buscando entrar o seguir de largo) de la época actual.

Un sino de indefinición ha marcado a fuego a nuestra época. Hemos tenido problemas para entender la dispersión acumulativa y situarla en un horizonte histórico siempre a continuación. ¿O en verdad la continuidad se ha roto y desde los núcleos del corte emigran realidades autónomas a las cuales no todo les da lo mismo, y por eso se aferran a su expansión disolutoria? Las palabras arremeten contra las evidencias del mundo empírico para dejarlas incumplidas. Pasan al lado de la realidad para mirarla fijamente desde lejos. De su perspectiva, la sintaxis y el vocabulario salen con sus propósitos transformados por la actividad. Las rigurosas construcciones, que en algunos casos pueden pasar por proposición matemática, hacen creer al lector que asiste a la película de un pensamiento indirecto en tiempo real. Hay un acto de liberación lingüística aconteciendo donde las palabras se reúnen para dar cabida a un habla espástica. Las palabras, precisamente, también ellas, tienen derecho a expresar lo que más tarde solo ellas serán capaces de entender.

El principio de la irrupción (principio tanto como punto de partida y causa primera de algo) hace hablar a las palabras en primera persona, desatendiendo cualquier responsabilidad que tuviera que ver con reivindicar un haz de significados que caracterizarían de manera sintética, pero definitiva, el 'contenido' de los poemas. No en vano, el énfasis sostenido en la digresión consigue sacar de sus casillas a la taxonomía, a cualquier intento por clasificar (aunque sin sistematizar, pues es lo que todavía falta) a ciertas poéticas con 
patrones comunes y catalogadas bajo el término "neobarroco". La poesía, el acto poético, es decir, la pauta de un orden acompañado de introducciones al caso, no ha logrado escapar a este proceso hoy tan largo como tedioso de etiquetar para poder comprender en "términos generales".

En tanto proclama de originalidad en voz alta, el neo-no-barroco (o barrococó) es contraseña de acceso a avatares del habla hasta entonces no permitidos o sin visitar. La escritura como consecuencia de un desarrollo y seguidamente de una singularidad, pero también entrada en puntas de pie al último escenario por ocupar de la modernidad concluyente. La entronización de actos reunidos incluye la adaptación a nociones irreductibles, a una disciplina de aptitudes que ejemplifica un pensar sobre el pensamiento. Cabría pues considerar al neo-no-barroco un romanticismo después de la abolición del Romanticismo, algo que por cierto todavía no ha sido decretado del todo. La escritura como acto de rodeo. El derecho a la palabra sin fines utilitarios y el rechazo a la ideología dominante, cualquiera sea, es una de las tesis principales. Además, queda destruida la noción de representatividad autoral, esto es, la falsa noción de que el poeta tiene algo para decir sobre el mundo y sobre sí mismo. Lo autobiográfico es desaconsejable. De ahí que una y otra vez se constata la persistencia de una clandestinidad del yo, ayudada en todos los casos por la proliferación de imágenes sacadas de quicio; las echan por la puerta y regresan entrando por la ventana.

La carga de escritura situada por encima de la desmesura, con enorme cantidad de dispositivos atribuidos a la aprobación de un mecanismo, apela a la capacidad atencional límite del lector, y hasta la rebasa. El efecto de saturación logra su objetivo. El poema es un objeto inasible. Es una creación absoluta, carente de ideología y sin relación alguna con la historia. En ese coloquio de interioridades disolventes queda abolida la ilusión de paradigma, destacándose la preeminencia del lenguaje como solitario acontecimiento en construcción. Una insistencia salta a la vista; el lenguaje se desplaza en tiempo irreal, todo lo opuesto a lo que ocurre, por ejemplo, con los reality shows, los cuales, por imponer una proliferación de puntos de perspectiva (dada por la multiplicidad de cámaras), una manera innumerable, exacerbada, de adentrarse en cierta realidad considerada la única realidad, también podría ser considerado un hecho neobarroco, aunque de carácter absolutamente efímero.

En la poesía neo-no-barroca advertimos la aparición de un pensamiento escrito que entroniza la forma de su diversidad, para permanecer en el "a través", en la visión donde coinciden un acto de composición y un paisaje retórico inconcebible sin su indeterminación, sin su paso por una combinación 
simultánea de factores. El histrionismo clausular lleva a las frases a vivir en una acelerada hipérbole, en una emboscada del exceso. Desde el interior de una gramática intransigente, el poema, en tanto ficción de su propia propuesta y representación de sus dudas, magnifica su solipsismo en la proliferación como destino reinventado una y otra vez, al cual todavía no pertenece y sin embargo, ya está ahí. Asume el propósito de ser la proposición que aún no consta, pero que impide ser sustituida.

Apegado a su rutilante actividad en la sintaxis, el poema neo-no-barroco acelera un salto de secuencias, donde factores itinerantes se combinan para crear una perspectiva, que es la del pensamiento mientras piensa. En su incesante continuidad, las evidencias -de las que vive la interpretación-quedan reducidas al máximo y refieren a lo que luego serán antes de haberlo dicho por completo, confirmando la incertidumbre que al privilegiar esparcen. Las palabras están de este lado de lo que sucede, haciendo lo imposible para que el periplo a través de la escritura se agote, existiendo como punto de partida sin saber cómo o por qué, y menos para qué, si igual son la posposición de un llegar a ser en la preexistencia de las frases. En el mundo, tal cual lo han encontrado, la suya es una evidencia circunstancial. En todo caso, es una variación a partir de su influencia.

El poema es una cámara captrópica, en donde una multitud de espejos clausulares reflejan significados cada uno perteneciente a una frase aislada que no se siente subordinada a la totalidad. El lingüista estadounidense Bruce Stiehm, en un artículo escrito sobre mi poesía ha dado en la tecla al hacer una afirmación aplicable a unas de las especificidades operativas clave del neo-no-barroco en sus diversas acepciones:

Es más bien un simulacro de sintaxis que utiliza estructuras suboracionales para dar la impresión de apuntar hacia una unidad sintáctica. Cada frase desemboca ilógicamente en otra función incongruente. El resultado es una oración inacabable, siempre abierta a extenderse en contacto con la continuidad de la experiencia (Stihem 120-121).

El poema escapa de sus trampas eludiendo las respuestas definitivas; sus descubrimientos están fuera de toda intención totalizadora, en todo caso, su asimétrico escenario es el único afán totalizante. Los límites del lenguaje están más allá de los límites del mundo donde las ideas representan la posposición del contenido, y también la interrogación de un proceso inagotable. Cancelación y continuidad anteceden al argumento de los ejemplos a ser encontrados. En más de un sentido, los poemas se defienden "de" sí mismos para conservar su 
forma, su estado de cambiante posibilidad sobre la cual el lenguaje insiste, para confirmar así su voz entre sus voces y la resonancia anterior al habla. La importancia de lo poco familiar se apoya en una estructura de sonidos, en una lógica fuera de la epistemología de las circunstancias de su existencia. Frases y sentido quedan incluidos en la situación de irrepresentabilidad que originan. De esta manera, el lenguaje rechaza la noción de absoluto, contentándose con integrar la poética de una situación a la cual antecede sin obedecer ni describir.

Acción de epifenómenos, de singularidades indirectas, el poema neono-barroco (barrococó) borra y reintroduce, manteniendo una ambivalente posición respecto al presente real donde interviene (no hay definición teórica, nada más que un modo de sospecha), exhibiendo aquello mismo ante lo que se rebela por ser lo contrario. Contemplación de una práctica de la cual procede la torrencialidad verbal, el poema representa el aprendizaje de la interrogación de todo aquello que es y que al mismo tiempo puede ser implicado por la falta de explicación y de tiempo específico donde situar su periplo por algún sitio, cuyo único compromiso es con la disimilitud. ¿Va o se queda y en su núcleo expande su ciclo?

La poesía neo-no-barroca hace colapsar la gama de certezas previas de quienes leen pensando que un contenido los guiará hasta un lugar del entendimiento con suficientes motivos como para complacer a la razón. La poesía, como acto de velocidad reinventada, no puede ser otra cosa que el momento culmen de un pensamiento peligrosamente sano, que deja los contenidos de la razón al borde del abismo, de un lugar carente de moderación. Salir de la uniformidad, de aquello que los formalistas rusos llamaban "el mundo tal cual es", significa producir variedad expresiva para darle cabida a la excepción, la que a su vez origina otras. Se escribe para cambiar los rasgos de la "poeticidad" contemporánea, para instalar frases no preposicionales ni parentéticas que observan al mundo como posibilidad distante, como epifanía imposible, pues no hay ninguna particular intención en hacer accesible al pensamiento, presentando de zigzagueante manera los fenómenos de la conciencia, en caso de que haya control autoral posterior a las primeras versiones de la escritura. El afán apunta a que el lector no se sienta confortable, ni que llegue con agenda previa al lenguaje ofrecido. El poema ya no puede ser como era, ni tampoco significar un mero intento por acceder a un interior blindado. Por supuesto, todo esto lleva a cuestionar qué es lo que convierte a un determinado texto en poema, y a replicar la idea de que todo puede ser poema y al mismo tiempo no serlo. 
Conviene recordar al respecto que el neo-no-barroco (barrococó) coexiste con prácticas de escritura poética alejadas de lo común, con computadoras programadas para escribir un poema, y reafirmar la noción lúdica de que fuera del control autoral del lenguaje suceden cosas lo más distantes posible de lo autobiográfico. Los desafíos intrínsecos de la poesía se han cargado de incertidumbre respecto a la dirección de la producción del poema y de ejecución de un habla directa con aspiraciones de "transparencia". Como contrapartida, la deriva sin inclusión de contenidos hace del lenguaje el ejemplo a replicar, sin anteponerle una definición a los resultados de su acto; el optimismo de la complicación triunfa; el yo autoral o poético se presenta desestabilizado, ilógico y experimental, fuera de la elocuencia secuencial, tras haber convertido la sintaxis en un campo minado de interrupciones, pues de lo que se trata es de llevar al lenguaje más allá de lo que dice; hacia un interés renovado en una dicción estricta, hacia un lugar del pensamiento con otras expectativas formales.

El acercamiento a lo arbitrario es bajo control, en estado restrictivo, siguiendo un compromiso no emocional con las formas que surgen "entre" y cuyo propósito es hacer que el poema sea algo más que una reunión azarosa de fragmentos bellos, tal como veía W.B. Yeats a la poesía moderna. Marjorie Perloff afirma que "las elecciones formales no son nunca sin implicaciones ideológicas" (3). Las implicaciones ideológicas de la desaparición del yo atañen a un cambio contrastante en la sociedad digitalizada, donde las reflexiones líricas sobre la sensibilidad de quien escribe carecen de importancia, pues ese espacio de comunicación ha sido ocupado por las redes sociales, por la rápida ventilación de las intimidades, como si la noción de existencia hubiera pasado a estar relacionada con el acto de hacer públicas las conductas, y de validar los propósitos para estar "en exposición". El cuerpo dejó de ser locatario de su intimidad. El yo, pues, se ha transformado en una entidad inquietante; es una evidencia demasiado natural como para ser continuada en el lenguaje. El deterioro de la revuelta personal, la sustitución del sujeto por la objetividad de perspectiva, empaña la linealidad lógico-deductiva, modificando cualquier gesto implícito de contención. Al sentirse restringida, la subjetividad se exacerba.

La poética neo-no-barroco (barrococó) resiste, se niega a ser un medio informativo de sentimientos y pareceres sobre la realidad empírica, la de los datos conteniendo los hechos de la historia. Hacerlo sería caer en una incongruencia, pues, ¿qué aspecto de la intimidad queda aún por exhumar en un poema de hoy en día, cuando la vida se acostumbró a vivir al descubierto, 
con redes sociales siempre prontas para profundizar en el strip tease y con comunicaciones personales hackeadas por piratas informáticos imposibles de localizar, quienes buscan conocer gustos y preferencias de los usuarios de internet, o bien a sentirse fisgoneada por servicios secretos al servicio de ideologías diferentes? En esa coexistencia de realidades intimidantes de la intimidad, ¿cómo hacer hablar a un yo interesante? Poca tolerancia hay para las confesiones, para el paradigma del sujeto hablando de cosas cotidianas y de los placeres o tristezas del presente, presentando un reportaje de sus actividades con emociones in crescendo que a nadie interesan, pues han sido oídas infinidad de veces en otra parte. La paradoja se instaló en la escritura: a la civilización del yo en estéreo, caracterizada por la súper información y la instantaneidad como concepto empírico, le ha dejado de interesar, por tanta sobreabundancia de intimidades expuestas, las comunicaciones personales de la poesía.

En la era digital, en la cual la recepción de la poesía es de por sí un acto creativo, la poesía no puede ser un confort para el entendimiento, un lugar a donde las voces vienen a hablar de sentimientos y relatar la vida cotidiana. De ahí que el poeta neo-no-barroco componga por apropiación y que su poesía sea una investigación que representa el estar vivo del ser. Es una práctica "creativa" no sujeta al sujeto; el poeta pasa a ser el otro que se incorpora al habla y es apropiado. Puesto que cita con variantes, apela al reciclaje, a la transcreación de otras fuentes, a la fotocopia de su propia poética, a comentarios abstractos sin informar su procedencia y ordenados arbitrariamente. En el lenguaje empresarial se habla de merger (fusión) de dos compañías. También en el poema neo-no-barroco (barrococo) constatamos un procedimiento fusional, aunque no efusivo. De ahí que esta pueda ser considerada una poesía intelectual a costa de sí misma, con mínima presencia de emociones, como si las palabras hubieran sido utilizadas para hacer desaparecer a quien las utilizó. Lo "lírico" (en tanto predominio de una realidad textual ocupada por la persona autoral) es puesto en tela de juicio; se le ha otorgado una fisonomía elíptica en lo expansivo, con estrofas de final repentino, carentes de instrucciones sobre cómo deben ser leídas.

El lenguaje arremete contra sí mismo para establecer un diálogo obstaculizado que impide el cumplimiento completo del acto comunicativo. La innovación se muestra de peculiar manera. Está en la repetición eufónica, en las fuentes primarias y secundarias eliminadas, en la yuxtaposición de partes recortadas a las que les dejó de interesar la regla dorada de la comunicación: que el mensaje 
sea rápidamente codificable. La poesía neo-no-barroca es una visualidad acústica que se descentra, una estructura autoconfesional, en el sentido de que solo habla de ella, no de quien la escribió. El tiempo del sonido y el sonido del tiempo cumplen con el mandato de John Cage respecto a que la poesía no es poesía "por razón de su contenido o su ambigüedad, sino en razón de permitir que sus elementos musicales (tiempo, sonido) se introduzcan en el mundo de las palabras". Según Cage, "algo" es un poema cuando no puede ser convertido en prosa, evitando, tal cual acota Perloff, "el paradigma del verso libre (observación, memoria desencadenante, entendimiento)" (8). Puesto que el poema es un ritmo y una melodía que quedan bien incluso en su ausencia, la página, las analogías, metáforas y símiles fácilmente pueden pasar a ser víctimas inmediatas del silencio. Algo rima dentro suyo sin decirlo. Hay que acercar el oído. ¿Qué quiere decir la sintaxis?

El poema se carga de una constelación de frases irreconocibles que prestan la misma atención al ojo que a la escucha, haciendo irreconocible al paisaje de las preposiciones y situando al acto de la lectura en los límites de la ilegibilidad; ¿cómo leer un paisaje sonoro, cómo hacer para que las palabras dejen de exceder a la incertidumbre? El poema, por ser una hipnótica máquina librada de cualquier responsabilidad paradigmática, reconstruye su trayectoria de sentidos y vacíos, haciendo que su énfasis recaiga en la arquitectura morfémica, en la voz implosiva que eclosiona; se borra y vuelve a surgir como instrumento anterior al significado. La espesura etimológica, la densidad sintáctica, son los materiales que componen el método, el pivot giratorio, su función en las antípodas de la funcionalidad.

El desdén por los hechos empíricos, por cualquier tipo de mirada fiel a lo supuestamente cierto de lo real, coincide con un rechazo a la poesía locutoria, en la cual el poeta emerge convertido en ventrílocuo de emociones; como heraldo epifánico y confesional de un yo con veleidades exhibicionistas. El poema neo-no-barroco instala en su interior un estado de alerta itinerante para crear por otros medios una belleza exclusivamente lírica, dando cabida a una sintaxis disyuntiva en donde emergen formas inesperadas de formalizar las formas, de situarlas a contramano del sentido. La poesía es una práctica de interferencia, aunque haya ejemplos recientes que indican, y redimensionan, la necesidad de recurrir en determinadas ocasiones a las voces de los sentimientos inmediatos (como los poemas de José Kozer dedicados 
a la muerte de su madre y de su padre), más no sea para generar una versión anti-sentimentalista de aquello mismo sobre lo cual se está escribiendo ${ }^{8}$.

En el itinerario con destino a un yo exclusivamente lingüístico se constata de manera unánime la inscripción de un decorado y el estímulo de un procedimiento que han logrado desterrar las semejanzas y que incluyen la coartada preparada para acceder a un interior que se nota mucho por ser incomparable, pero que no deja atraparse por la interpretación, en todo caso, por un razonamiento exclusivamente rítmico. Ni siquiera en los momentos frásticos cuando pareciera que va a esbozarse una historia, un relato cuya verdad es de antemano relativa y puede ser negada por un método exclusivamente poético, puede hablarse de una secuencialidad en plan disertativo, la cual caracteriza a la mayoría de la tan previsible poesía de este comienzo de siglo, 'yoica' y referencial, y que proyecta la idea de estar diciendo algo importante, incluso cuando no lo dice (que es la mayoría de las veces). Con su linealidad dispersiva, preocupada en ir a todas partes, la poética neo-no-barroca impulsa su unidad en la fragmentación, en las lecciones de distracción carentes de objetividad, en su constante recurrir a la impersonalizacion del sujeto autoral. La transitividad y lo desiderativo establecen un habla asistemática, única manera de librar a la creatividad de su acotamiento.

En la conferencia "The Poet", dictada en Nueva York el 5 de marzo de 1842 y publicada en el libro Essays: Second Series (1844), Ralph Waldo Emerson consideró a los poetas “dioses liberadores". Algunos aún lo son. Han venido a liberar a las palabras de cualquier responsabilidad comunicacional inmediata y al mismo tiempo a incluirlas en desplazamiento admonitorio, dentro del cual las frases no dan nada por hecho. Al establecer una normativa rítmica y lexical, un amontonamiento sintáctico, el poema neo-no-barroco se transforma en un verdadero parque de atracciones clausulares. Tal vez

\footnotetext{
Algo similar ha pasado con tres poetas relacionados con $\mathrm{L}=\mathrm{A}=\mathrm{N}=\mathrm{G}=\mathrm{U}=\mathrm{A}=\mathrm{G}=\mathrm{E}$ y la poesía del Lenguaje estadounidense, caracterizada, entre otras cosas, por su antisentimentalismo: Susan Howe (1937), Charles Bernstein (1950) y Peter Gizzi (1959). Han publicado recientemente libros que contienen poemas sobre la muerte de seres queridos. Susan Howe publicó That This (2010), un largo poema en prosa sobre la muerte de su marido, el filósofo Peter Hare; en Recalculating (2013), Bernstein incluyó poemas dedicados a su hija Emma Bee, muerta muy tempranamente; y Peter Gizzi dedicó Threshold Songs (2012) a la memoria de su madre, de Michael, su hermano y de Robert, un amigo suyo cercano. La investigadora estadounidense Diane Rolnick dedicó una extraordinaria tesis a este tema: In the Name of the Father and the Mother. Mourning Memory, and Imagination in the Poetry of José Kozer, Tamara Kamenszain and Eduardo Espina (2015).
} 
únicamente esté representando la forma de comportarse de un optimismo o el advenimiento de una pretensión de totalidad innovadora. Proyecta la idea de que lo que está sucediendo en su interior sucede por primera vez en el momento que lo está leyendo el lector. Este siente que ha logrado hackear el blindado sistema frástico. En medio de la neurosis digital, de la utopía del avatar y de la estética del Photoshop que caracterizan a nuestra época, las frases no dan nada por hecho y en sus modulaciones reafirman una permanencia en la sintaxis, pues allí las frases ejercen un pensamiento propio, que hasta el momento mismo de ser escrito no tenía la más remota idea de su existencia.

El poema neo-no-barroco (barrococó) es por consiguiente una instancia que suscita y satura, indicio recuperado de un detalle expansivo que solo puede ser verificado en la continuidad de la cual se ocupa, como diciendo que no estamos tan lejos de inventar "nuevas lógicas" de escritura y lectura. En medio de la mecánica incomprensible de la época, la misma que ha hecho imposible imaginar la vida más allá de la tecnología, descuella una realidad textual que ha llegado cuando menos se la esperaba. Al privilegiar los desaires de lo incompleto, de presentar una panorámica del futuro con sus "incongruencias" y datos que dejaron de coincidir con lo esperado, el poema representa una tentativa de indecisión ocupada por realidades diversas ocurriendo a la misma vez y sin parar de ocurrir.

Al evitar las verdades sensacionalistas del yo, el poema privilegia un material abierto cuya descripción cambia de significado y adquiere otros a medida que las frases transcurren sin avizorar condiciones. La cartografía de lo aparentemente incomprensible permite rastrear en la enunciación lugares distantes de lo común. Como si fueran abejas agrupadas en apariencia caótica al entrar al panal, los tramos clausulares acontecen de manera yuxtapuesta, y al superponerse dan la impresión de estar borrándose. La probabilidad de verosimilitud queda en manos de los acontecimientos lingüísticos. De ahí que la poesía neo-no-barroca proyecte con insistencia la idea de ser la invención de una perspectiva: a través de una ventana no está viendo la realidad, sino el paisaje de un pensamiento.

Hemos insistido en la necesidad de aclarar el término "neobarroco", de agregarle acepciones que lo alejen de su mentado parentesco directo con el barroco español y llamarlo mejor neo-no-barroco o barrococó, pues sus puntos de contacto con una diversidad en desarrollo son más plurales y no han sido tan tenidos en cuenta hasta el presente, como su más que evidente relación con la poesía post-romántica francesa, Lautréamont sobre todo, pero también con la literatura innovadora, críptica y original de Lewis Carroll, especialmente 
el poema "Jabberwocky". Epítome del non-sense, "Jabberwocky" aparece incluido en A través del espejo y lo que Alicia encontró allí (1871). Gran cuota de los vocablos que lo componen fue inventada por Lewis Carroll, palabras (fusiones y neologismos) que luego quedaron incorporadas al idioma inglés, no sin antes generar desconcierto y frustración en el receptor que entra (mal entrenado) al poema, como si este fuera un reservorio a donde ir a encontrar respuestas a las expectativas generadas por la lectura. Alicia lee un libro de poesía, pero las palabras están invertidas, por lo que solo podrá leerlas (aunque no necesariamente entenderlas) si las refleja en un espejo. Comienza leyendo esto: "Twas brillig, and the slithy toves/Did gyre and gimble in the wabe; /All mimsy were the borogoves, / And the mome raths outgrabe". Después de ese comienzo, traducido también como "Asurraba. Los viscovivos toves" y "Asardecía y las pegájiles tovas"10 ¿cómo seguir? Mejor dicho, ¿hacia dónde?

En "Jabberwocky" las palabras, en tanto unidades morfológicas trascendentes por sí solas (sin estar obligadas a acoplarse con finalidad teleológica a las cláusulas), imposibilitan la búsqueda de un significado, dificultando incluso la pronunciación. De la misma forma, la poesía neo-no-barroca actúa como divertimento del pensamiento que sigue las trazas de las redes semánticas que el lenguaje va emitiendo en busca de preguntas para la respuesta que ya encontró. El lenguaje entra muy campante a un pensamiento que rechaza la linealidad lógica-deductiva, siendo por lo tanto crítico del logos y no lapsus de este. Magma de yuxtaposiciones recargadas de volutas sin jerarquías previas, tiovivo no obediente a pautas racionales, el poema enfatiza las torsiones de un idioma reinventado que parece ir a la deriva a toda velocidad, cabal sprinter de sus filologías, pero que sigue con firmeza proteica el rumbo impuesto desde el primer verso, caracterizado por un borroso fondo abstracto y por el atonalismo musical, por frases a las que todo no les da lo mismo, porque ponen en jaque incluso lo que supuestamente expresan, aunque respetan las indicaciones de un pensamiento inquieto, itinerante, que solo piensa sobre aquello que quiere decir, por más que lo piense recién después de haberlo dicho.

\footnotetext{
"Calentoreaba, y las viscotivas tovas / vuelteaban y tregujereaban el terecho. / Misébiles estaban los borogovas / y los deros trugones bramastoilbaban", en la versión española hecha por el traductor argentino Eduardo Stilman (18).

10 Versiones de Juan González Álvaro, y Mirta Rosenberg y Daniel Samoilovich, respectivamente: http://juegosdeingenio.org/archivo/949
} 
La poesía neo-no-barroca complace las manías de polivocidad de frases y palabras, en consonancia con un ritmo no relegable y de movimiento pendular, que desaparece y reaparece, como si en el no pero quizá si, en ese intersticio tan inasible, residiera el núcleo de la poética. Quintaesencia de un magistral manejo de la ambivalencia, la poesía neo-no-barroco o barrococó (a partir de ese pionero registro que fue "La Torre de las Esfinges", de Julio Herrera y Reissig, en 1909) muestra el progreso de la melodía de frases con algo no decible, para las cuales los límites de la expresividad se han corrido, con todo el terreno despejado por delante. Mensajero de una exageración condescendiente, de una distracción intencional y ampliada, lo mismo que el poema de Carroll (de quien también podría mencionarse The Hunting of the Snark, libro muy bien leído por Neruda para escribir Residencia en la Tierra y tal vez por ello lo mencione en Confieso que he vivido), el caudal lingüístico sale a la caza de acontecimientos fuera de lo habitual en su versión inicial. El lenguaje se hace eco de sentidos y pensamientos presentados como distinción de una sintaxis, que es la fuerza instructiva del procedimiento.

Situada en circunstancias efímeras, en una zona temporal implacable sin dejar de ser inmediata, la escritura se carga de indicaciones persuasivas, cuyo objetivo no es ni por asomo domesticar lo aún no resuelto, ni tampoco incluirlo en un relato. Quizá ya no estemos en el "ciclo de los nervios", como creía Vicente Huidobro, pero la poesía sigue anhelando que la mente establezca ciclos, esta vez alguno correspondiente a la era de la hipertextualidad, la que acecha con preguntas intermitentes, entre otras la siguiente: ¿de qué manera, cómo, "ver" la escritura desde un instante fenomenológico que rehúsa ajustarse al proceso de la atención? Las únicas responsabilidades de la poesía, tal como esta poética tan contundente lo destaca, son con la forma de percibir al lenguaje en actividad y de resolver de manera menos específica las descripciones de lo real y de lo imaginado, como si se tratara de cambiar los muebles de la casa para que haya más espacio, o dar al menos esa impresión.

Algo similar a la recordada frase dicha por Johnny Carter en "El perseguidor", de Julio Cortázar: "Esto lo estoy tocando mañana (...) Esto ya lo toqué mañana", podrían decir los poetas neo-no-barrocos. Trajeron a su época de presente continuo una poética futura. En tiempos como los actuales, de excesiva tranquilidad estética, cuando todavía se sigue leyendo la poesía mediante la "explicación del texto", la poética neo-no-barroca representa un zarpazo de innovación, de originalidad en cuanto inventa perspectivas, imponiendo una ahistoricidad metódica, autosuficiente, atemporal. Un enjambre sintáctico depredador dificulta la referencialidad, en todo caso, 
la hace aparecer en otro nivel de dicción, como propuesta de lectura crítica al borde de la descalificación. A ese ritmo sin contradicción, con el cual la poética se identifica, viene a unírsele una diversidad de factores convocados para resistir la descripción, como también el traslado de significados de una zona a otra del poema.

Dando cuenta de la transitoriedad de un trance (dentro del cual puede oírse la "música interior del habla" aludida por Paul Valéry) desprovisto de contraseñas, de un movimiento que activa más movimiento (del pensamiento), la escritura neo-no-barroca o barrococó logra permanecer resonante, incluso cuando se dejó de prestarle atención. Ese resultado sin específicos, de apelación inmediata a la mente y a una tonada librada de sentimentalismos, y que produce interferencias en las cosas que le pasan al lenguaje, no tiene un origen exclusivamente barroco, tal como es evidente. Ya no es solamente neobarroco. Entonces, ¿qué nombre darle a lo que no se había hecho y que camino a su resolución como tesitura difícil se fue cargando de procedencias diversas? ¿En qué tradición literaria incluirlo?

\section{BIBLIOGRAFÍA}

Carroll, Lewis. Through the Looking Glass, and What Alice Found There. Mincola, Nueva York: Dover Thrift Editions, 1999.

Deleuze, Gilles. Le pli: Leibniz et le Baroque. Paris: Les Editions de Minuit, 1988.

Echavarren, Roberto, José Kozer y Jacobo Sefamí. Medusario: muestra de poesía latinoamericana. México: Fondo de Cultura Económica, 1996.

Green, Robert, and Stephen Cushman, eds. Princeton Encyclopedia of Poetry and Poetics: Fourth Edition. Princeton: Princeton University Press, 2012.

Janik, Allan y Stephen Toumlin. Wittgenstein's Vienna. London: Weidenfeld and Nicolson, 1973.

Perloff, Marjorie. "Poetry on the brink. Reinventing the Lyric", May 18, 2012, http://www. bostonreview.net/forum/poetry-brink (1-9).

Stiehm, Bruce. "Imagen multivalente y oración calidoscópica en la poesía de Eduardo Espina". Tradición y actualidad de la Literatura Iberoamericana: Actas Del XXX Congreso Del Instituto Internacional De Literatura Iberoamericana. Pittsburgh: University of Pittsburgh (1995): 117-129.

Stilman y Best, Eduardo. Los libros de Alicia. Pról. Jorge Luis Borges. Buenos Aires: Ediciones de la Flor, 1996.

Von Ficker, Ludwig. Briefwechsel, 1914-1925. Innsbruck: Haymon, 1988. 